\title{
ANALISIS MODEL LOYALITAS PASIEN DI RSUD DR. RASIDIN PADANG DENGAN TEKNIK STRUCTURAL EQUATION MODELING (SEM)
}

\author{
GUSMANELY, FERRA YANUAR, DODI DEVIANTO \\ Program Studi Magister Matematika, \\ Fakultas Matematika dan Ilmu Pengetahuan Alam, Universitas Andalas, \\ Kampus UNAND Limau Manis Padang, Indonesia. \\ email : elygusmanely@gmail.com
}

\begin{abstract}
Abstrak. Salah satu upaya pemerintah dalam meningkatkan kesejahteraan rakyat adalah dengan pembangunan pelayanan kesehatan. Melalui pembangunan pelayanan kesehatan ini diharapkan juga akan semakin meningkatkan derajat kesehatan masyarakat. Pelayanan kesehatan dapat ditinjau dari persepsi kepuasan dan loyalitas masyarakat terhadap kualitas pelayanan. Penelitian memberikan model loyalitas pasien pada RSUD dr. Rasidin Padang dengan menggunakan teknik structural equation modeling (SEM). Teknik SEM ini mempunyai kemampuan untuk menerangkan hubungan antara variabel indikator dan variabel laten secara serentak. Data yang digunakan adalah data primer sebanyak 150 sampel yaitu responden yang pernah dan sedang mendapatkan layanan kesehatan di RSUD dr. Rasidin Padang sejak Januari 2014. Pengumpulan data primer ini dilakukan pada bulan April sampai Mei 2014. Penelitian ini menghasilkan bahwa kepuasaan pasien terhadap layanan kesehatan di RSUD dr. Rasidin Padang berpengaruh secara signifikan terhadap loyalitas pasien. Sedangkan kualitas pelayanan mempengaruhi loyalitas secara tidak langsung, dengan faktor kualitas pelayanan sebagai mediator antara kedua faktor tersebut. Oleh karena itu untuk meningkatkan loyalitas masyarakat untuk datang berobat ke rumah sakit maka tingkat kepuasaan dan kualitas pelayanan harus ditingkatkan. Berdasarkan indikator kebaikan model, dapat ditunjukkan bahwa model hasil analisis telah menyesuaikan data dengan baik dengan demikan model loyalitas pasien yang dihasilkan dapat diterima.
\end{abstract}

Kata Kunci: Model loyalitas pasien, Structural Equation Modeling (SEM), kualitas pelayanan, kepuasan pasien

\section{Pendahuluan}

Peningkatan pelayanan kesehatan sangat diharapkan oleh masyaraktat, dengan adanya perbaikan kualitas pelayanan kesehatan yang baik menyebabkan masyarakat akan puas dan loyal terhadap pelayanan. Loyalitas atau kesetiaan berhubungan dengan sikap dan perilaku konsumen terhadap produk yang ditawarkan. Oliver (1997) menyatakan bahwa loyalitas dari aspek perilaku adalah komitmen seorang konsumen untuk membeli produk atau jasa yang sama walaupun dipengaruhi oleh situasi dan tawar-tawaran pemasaran yang dilakukan oleh perusahaan lain yang memiliki potensi produk atau jasa yang sama walaupun dipengaruhi oleh situasi dan tawar-tawaran pemasaran yang dilakukan oleh perusahaan lain yang memiliki potensi bagi beralihnya konsumen dimaksud.

Menurut Zineldin (2000) menyatakan bahwa kepuasan adalah keseluruhan sikap 
pelanggan terhadap penyedia layanan atau sebuah reaksi emosional pada perbedaan antara apa yang diantisipasi (diharapkan) dan yang dirasakan. Kepuasan pelanggan merupakan kunci dalam menciptakan loyalitas pelanggan. Banyak manfaat yang diterima oleh perusahaan dengan tercapainya tingkat kepuasan pelanggan yang tinggi, yakni selain dapat meningkatkan loyalitas pelanggan tapi juga dapat mencegah terjadinya perputaran pelanggan, mengurangi sensitivitas pelanggan terhadap harga, mengurangi biaya kegagalan pemasaran, mengurangi biaya operasi yang diakibatkan oleh meningkatnya jumlah pelanggan, meningkatkan efektivitas iklan, dan meningkatkan reputasi bisnis (Fornell, 1992). Dengan adanya kualitas pelayanan yang baik dalam suatu perusahaan, akan menciptakan kepuasan bagi para konsumennya. Setelah konsumen puas dengan produk atau jasa yang diterimanya, konsumen akan membandingkan dengan pelayanan yang diberikan. Apabila konsumen merasa benar-benar puas, mereka akan memberikan rekomendasi kepada orang lain untuk membeli di tempat yang sama. Oleh karena itu, perusahaan harus mulai memikirkan pentingnya pelayanan pelanggan secara lebih matang melalui kualitas pelayanan, karena kini disadari bahwa pelayanan dan kepuasan pelanggan merupakan aspek vital dalam bertahan didunia bisnis untuk memenangkan persaingan (Tjiptono, 2006).

Sebagaimana diketahui bahwa pelayanan bidang kesehatan ini merupakan salah satu dari tiga pelayanan dasar bersama pendidikan dan pemenuhan kebutuhan pokok yang perlu untuk terus diteliti, dievaluasi dan dikembangkan. RSUD Dr. Rasidin dipilih sebagai tempat pelaksanaan penelitian karena terdapat kecenderungan penurunan penggunaan RSUD ini sejak beberapa tahun belakangan. Untuk pasien yang berasal dari golongan ekonomi atas sangat sedikit jumlahnya yang datang berobat ke RSUD ini. Mereka lebih menyukai untuk pergi berobat ke rumah sakit swasta di Kota Padang atau bahkan pergi ke Jakarta atau ke luar negeri. Untuk itu perlu dilakukan kajian untuk mengetahui persepsi masyarakat terhadap pelayanan di RSUD Dr. Rasidin Padang dan apa saja yang menjadi persepsi masyarakat dalam memilih rumah sakit sehingga mereka mau dan loyal datang berobat di rumah sakit tersebut.

Teknik yang cocok untuk mengetahui dan menganalisis faktor-faktor yang berpengaruh dalam memodelkan loyalitas mayarakat adalah Structural Equation Modeling (SEM). Structural Equation Modeling merupakan metode analisis multivariat yang digunakan untuk menggambarkan keterkaitan hubungan linier secara simultan antara variabel pengamatan (indikator) dan variabel yang tidak dapat diukur secara langsung (variabel laten) serta hubungan antara variabel-variabel laten baik secara langsung maupun tidak langsung.

\section{Data dan Metode Penelitian}

Penelitian dilaksanakan di RSUD DR Rasidin Padang yang terletak di Jalan Air Paku By Pass KM 11, Kota Padang. Adapun data yang digunakan dalam penelitian ini adalah data primer yang diperoleh langsung dari sumber asli (tanpa melalui perantara) dengan menggunakan metode survei. Data primer yang ada dalam penelitian ini merupakan data kuesioner dari responden. 
Ferdinand (2000) menyebutkan bahwa pedoman ukuran sampel tergantung pada jumlah indikator dikali 5 sampai 10. Karena indikator dalam penelitian ini sebanyak 14 indikator maka minimal sampelnya sebesar 70. Selanjutnya Hair dkk. (1995) dalam Ferdinand (2002, p. 47), besarnya sampel bila terlalu besar akan menyulitkan untuk mendapatkan model yang cocok, disarankan ukuran sampel yang sesuai antara 100 - 200 responden agar dapat digunakan estimasi dengan SEM. Sehingga peneliti mengambil sampel sebanyak 150 responden karena model SEM ukuran sampel ukuran sampel yang sesuai adalah 100-200. 150 responden itu yaitu masyarakat yang pernah dan sedang mendapatkan pelayanan di RSUD DR Rasidin Padang sejak Januari 2014. Adapun profil dari 150 responden disajikan dalam Gambar 1 berdasarkan variabel umur, jenis kelamin, pendidikan terakhir dan pekerjaan utama.

\begin{tabular}{|c|c|c|c|}
\hline Variabel & Kategori & Frekuensi & Persentase \\
\hline \multicolumn{4}{|l|}{ Umur } \\
\hline & Kurang dari 27 tahun & 27 & 18.0 \\
\hline & $28-37$ tahun & 34 & 22.7 \\
\hline & $38-47$ tahun & 41 & 27.3 \\
\hline & $48-57$ tahun & 26 & 17.3 \\
\hline & 58 tahunke atas & 22 & 14.7 \\
\hline \multicolumn{4}{|c|}{ Jenis Kelamin } \\
\hline & Laki-laki & 52 & 34.7 \\
\hline & Perempuan & 98 & 65.3 \\
\hline \multicolumn{4}{|c|}{ Pendidikan } \\
\hline & SD Kebawah & 31 & 20.7 \\
\hline & SMP sederajat & 28 & 18.7 \\
\hline & SMA sederajat & 64 & 42.7 \\
\hline & D1-D2-D3-D4 & 9 & 6.0 \\
\hline & S1 & 17 & 11.3 \\
\hline & S2 Keatas & 1 & 0.7 \\
\hline \multicolumn{4}{|c|}{ Pekerjaan Utama } \\
\hline & PNS/TNI/POLRI & 11 & 7.3 \\
\hline & Pegawai Swasta & 8 & 5.3 \\
\hline & Wiraswasta/Usahawan & 19 & 12.7 \\
\hline & Pelajar/Mahasiswa & 9 & 6.0 \\
\hline & Lainnya & 103 & 68.7 \\
\hline
\end{tabular}

Gambar 1. Frekuensi dan Persentase Identitas Responden RSUD

Berdasarkan tabel pada Gambar 1 diketahui bahwa responden yang dilibatkan dalam penelitian ini paling banyak berumur antara 38-47 tahun (27.3\%). Mayoritas responden yang terlibat adalah berjenis kelamin perempuan (65.3\%). Sedangkan deskripsi berdasarkan tingkat pendidikan, paling banyak responden yang terlibat hanya berpendidikan SMA sederajat, yaitu 42.7\%. Sementara itu untuk pekerjaan utama, kebanyakan dari responden memiliki jenis pekerjaan "lainnya" (68.7\%) yaitu jenis pekerjaan yang tidak dikategorikan dalam kuesioner. 


\section{Pembuatan Model Hipotesis}

Setelah data diperoleh selanjutnya akan dianalisis sesuai dengan prinsip metode kuantitatif ekplanatif yaitu dengan mendeskripsikan variabel-variabel yang terlibat yang diperoleh dengan menelah seluruh data.

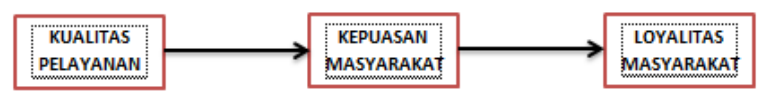

Gambar 2. Model Analisa

Pada tabel di Gambar 3 terlihat bahwa ada tiga variabel yang merupakan variabel laten. Variabel laten kualitas pelayanan ini akan diukur oleh variabel indikator kehandalan, daya tanggap, jaminan, empati dan bukti fisik. Untuk variabel laten kepuasan masyarakat diukur dari variabel kesesuaian tarif, kepuasan dengan dokter, perasaan senang, sesuai harapan, pelayanan keseluruhan memuaskan. Sedangkan untuk variabel loyalitas masyarakat juga memiliki variabel indikator yang mengukurnya yaitu niat merekomendasikan, kualitas word of mount, menceritakan hal positif, dan mengajak rekan.

\begin{tabular}{|c|c|c|c|}
\hline & $\begin{array}{l}\text { Variabel } \\
\text { Latent }\end{array}$ & Variabel Indikator & Lambang \\
\hline \multirow[t]{5}{*}{ Eksogen } & \multirow{5}{*}{$\begin{array}{c}\text { Kualitas } \\
\text { Pelayanan }\end{array}$} & Kehandalan & $\mathrm{X} 1$ \\
\hline & & Daya tanggap & $\mathrm{X} 2$ \\
\hline & & Jaminan & $\mathrm{X} 3$ \\
\hline & & Empati & $\mathrm{X} 4$ \\
\hline & & Bukti fisik & $\mathrm{X} 5$ \\
\hline \multirow[t]{9}{*}{ Endogen } & \multirow{5}{*}{$\begin{array}{c}\text { Kepuasan } \\
\text { Masyarakat }\end{array}$} & Kesesuaian tarif & Y1 \\
\hline & & Kepuasan dengan dokter & $\mathrm{Y} 2$ \\
\hline & & Perasaan senang & Y3 \\
\hline & & Sesuai harapan, & Y4 \\
\hline & & Pelayanankeseluruhan memuaskan & Y5 \\
\hline & \multirow{4}{*}{$\begin{array}{c}\text { Loyalitas } \\
\text { Masyarakat }\end{array}$} & Niat merekomendasikan & Y6 \\
\hline & & Kualitas word of mount & Y7 \\
\hline & & Menceritakan hal positif, & Y8 \\
\hline & & Mengajak rekan & Y9 \\
\hline
\end{tabular}

Gambar 3. Spesifikasi Variabel

Akan dianalisis juga variabel-variabel indikator yang mempunyai pengaruh yang signifikan terhadap variabel latentnya masing-masing serta bagaimana bentuk pengaruh tersebut. Model hipotesis yang akan diuji pada kajian ini diilustrasikan pada diagram jalur berikut.

Dalam penelitian kualitatif, terdapat dua jenis hipotesis, yaitu hipotesis satu variabel dan hipotesis dua atau lebih variabel (Cooper dan Schindler, 2006). Adapun hipotesis dalam penelitian ini adalah 


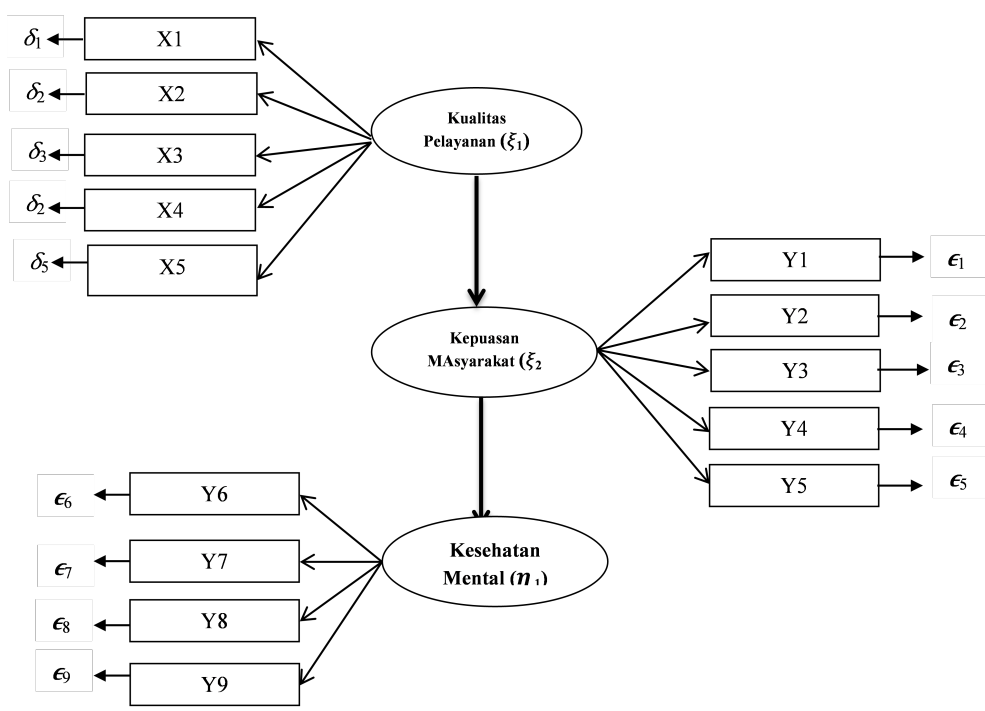

Gambar 4. Model Hipotesis Loyalitas Masyarakat di RSUD DR Rasidin Padang

H1: terdapat pengaruh kualitas pelayanan RSUD terhadap kepuasan masyarakat

Ada beberapa peneliti yang menyatakan bahwa ada pengaruhi antara kualitas pelayanan dengan kepuasan masyarakat yaitu Fullerton dan Taylor (2002) membuktikan bahwa terdapat hubungan yang erat antara kualitas pelayanan dengan kepuasaan masyarakat.

H2: Terdapat pengaruh kepuasan masyarakat terhadap loyalitas masyarakat

Manfaat spesifik dari kepuasan yaitu adanya keterkaitan positif dengan loyalitas pelanggan (Caruana, 2002). Penelitian lain menemukan bahwa kepuasan konsumen yang tinggi akan menyebabkan tingginya loyalitas (Boulding, 1993).

\section{Langkah-langkah Pemodelan Dengan Teknik SEM}

Dalam proses pemodelan SEM terdapat empat tahap, yaitu :

(o) Model Spesifikasi.

Untuk melakukan tahap pertama, SEM melibatkan dua komponen model utama, yaitu model pengukuran dan model berstruktur. Ekspresi secara matematik untuk model pengukuran adalah:

$$
x_{i}=\Lambda \xi_{i}+\epsilon_{i}, i=1,2, \cdots, n,
$$

dimana $x_{i}$ adalah vektor variabel indikator berukuran $p \times 1$, yang dihubungkan dengan vektor variabel laten eksogen $\xi_{i}$ berukuran $q \times 1$, yang 
diasumsikan berdistribusi $\mathrm{N}(\theta, \Phi), \Lambda$ adalah matrik keofisien regresi berukuran $p \times q$, yang diperoleh dari regresi setiap $x_{t}$ terhadap $\xi_{i}$, sedangkan $\epsilon_{i}$ adalah vektor acak untuk galat pengukuran yang berukuran $p \times 1$. Vektor acak $\epsilon_{i}$ diasumsikan saling bebas dan diasumsikan berdistribusi $N\left(0, \Psi_{\epsilon}\right)$ serta tidak berkorelasi dengan variabel laten $\xi_{i}$.

Hubungan antara variabel laten diterangkan dalam model berstruktur, formula umum secara matematiknya adalah sebagai berikut:

$$
\eta_{i}=B \eta_{i}+\Gamma \xi_{i}+\delta_{i}, i=1,2, \cdots, n,
$$

dimana $\eta_{i}$ adalah vektor acak dari variabel laten endogen berukuran $m \times 1$, $B$ adalah matrik koefisien berukuran $m \times n$ yang menghubungkan sesama variabel laten endogen, $\Gamma$ adalah matrik koefisien berukuran $m \times n$ yang menghubungkan variabel laten endogen dan eksogen dalam model berstruktur, dan $\delta_{i}$ adalah vektor acak berukuran $m \times 1$ untuk galat berstruktur, dan diasumsikan menyebar $N\left(0, \Psi_{i}\right)$ dimana $\Psi_{i}$ adalah diagonal dari matrik kovarian. Variabel $\xi_{i}$ diasumsikan tidak berkorelasi dengan $\delta_{i}$. Misalkan $\Lambda_{\omega}=(B, \Gamma)$ dan $\omega_{i}=\left(\eta_{i}, \xi_{i}\right)$ maka persamaan (4.1) dapat ditulis sebagai $\eta_{i}=\Lambda_{i}+\delta_{i}$.

(०) Model Estimasi.

Tujuan umum dari teknik SEM adalah menguji hipotesis apakah matriks varian kovarian untuk observasi yang diperoleh dari beberapa variabel indikator sama dengan matriks varian kovarian dari model hipotesis. Tujuan tersebut dapat diformulasikan sebagai:

$$
\Sigma=\Sigma(\theta)
$$

dimana $\Sigma$ merupakan matriks varian kovarian populasi dari beberapa variabel indikator dan $\Sigma(\theta)$ merupakan matriks varian kovarian populasi sebagai fungsi dari $\theta$ atau biasa disebut juga dengan matriks hipotesis. $\theta$ adalah sebuah vektor yang terdiri dari parameter-parameter yang akan diestimasi nilainya dalam model, seperti nilai-nilai mean, varian dan kovarian, koefisien regresi dan galat atau faktor pengganggu.

Dalam model estimasi, $\Sigma$ diestimasi oleh matriks varian kovarian sampel, dilambangkan dengan S, yaitu matriks pengestimasi yang konsisten dan tidak bias dari $\Sigma$. Sehingga tujuan dari model estimasi estimai adalah untuk meminimumkan perbedaan antara matriks S dan $\Sigma(\theta)$ dengan fungsi pemadanan $F(S, \Sigma(\theta))$.

(०) Penilaian Model.

Penilaian model bertujuan untuk mengidentifikasi ada tidaknya masalah pengidentifikasian berdasarkan penilaian terhadap hasil estimasi yang dilakukan program SEM. Beberapa indikator kebaikan model yang sering digunakan adalah nilai RMSEA (Root Mean Square Error of Aproximation), TLI (Tuckey Lewis Index) dan CFI (Comparative Fit Index).

(o) Modifikasi Model Penilaian Model.

Model perlu dimodifikasi jika matriks varian kovarian yang diestimasi oleh 
model tidak dapat menghasilkan matriks varian kovarian sampel yang memenuhi indikator kebaikan model.

\section{Hasil Pembahasan}

\subsection{Uji Validasi dan Reliabilitas Instrumen}

Sebelum melakukan penelitian, peneliti melakukan uji instrumen, yaitu dengan menguji validitas dan realibilitas dari instrumen yang akan digunakan. Adpun interumen yang digunakan dalam penelitian ini adalah instrumen kuesioner. Untuk pengujian validitas instrumen penelitian menggunakan teknik korelasi product moment. Pengujian validasi dapat dirumuskan sebagai berikut.

$$
r_{\text {hit.j }}=\frac{n \sum X_{i j} Y_{i}-\left(\sum X_{i j}\right)\left(\sum Y_{i}\right)}{\sqrt{n \sum X_{i j}^{2}-\left(\sum X_{i j}\right)^{2}} \sqrt{\left[n \sum Y_{i}^{2}-\left(\sum Y_{i}\right)^{2}\right]}},
$$

dimana:

$n$ : banyak observasi,

$X_{i j}$ : skor pernyataan ke $j$ untuk responden (individu) ke $-i, j=1,2, \cdots, k, i=1,2, \cdots, n$,

$Y_{i}$ : nilai total skor pernyataan untuk responden (individu) ke $-i, i=1,2, \cdots, n$.

Suatu pernyataan dapat dikatakan valid apabila $r_{\text {hitung }}$ sama dengan $r_{k r i t i k}$, dimana $r_{k r i t i k}$ merupakan nilai kritis pengujian. Solimun (2002) menyatakan bahwa apabila koefisien korelasi antar skor suatu pertanyaan atau indikator dengan skor total seluruh indikator $>0,30$ maka instrumen penelitian dianggap valid. Dari hasil pengujian validitas instrument diperoleh semua indikator valid untuk semua indikator. Sehingga tidak ada indikator yang harus dihilangkan. Sedangkan untuk mengetahui seberapa besar keterandalan suatu alat ukur dapat diketahui dari nilai reliabilitasnya. Reliabilitas merupakan suatu indeks yang menunjukkan sejauh mana suatu alat pengukur dapat diandalkan atau dipercaya. Reliabilitas diukur dengan menggunakan koefisien Alpha Cronbach $\left(C_{\alpha}\right)$ yang didefinisikan sebagai:

$$
C_{\alpha}=\left(\frac{k}{k-1}\right)\left(1-\frac{s_{i}^{2}}{s_{t}^{2}}\right)
$$

dimana:

$$
\begin{aligned}
k & : \text { jumlah item pernyataan, } \\
s_{i}^{2} & : \text { variansi setiap item pertanyaan atau pernyataan, } \\
s_{t}^{2} & : \text { variansi skor total pertanyaan atau pernyataan. }
\end{aligned}
$$

Instrumen dianggap reliabel atau andal jika keofisien Alpha Cronbach $\left(C_{\alpha}\right)$ bernilai 0,60 (Malhotra, 2004). Jika nilai Alpha Cronbach $(\alpha)$ semakin mendekati satu berarti bahwa konsisten jawaban semakin tinggi, artinya instrumen penelitian semakin baik atau andal (Hair, et al, 2006). Hasil dari uji reliabilitas instrumen diperoleh nilai keofisien Alpha Cronbach $\left(C_{\alpha}\right)$ bernilai 0,60 untuk semua indikator. Ini berarti bahwa instrumen yang akan digunakan telah valid dan memiliki reliabel yang cukup baik sehingga tidak perlu dilakukan modifikasi sebelum digunakan. 


\subsection{Analisis Model Loyalitas Masyarakat terhadap Pelayanan di RSUD dengan Teknik SEM}

Pada bagian ini dilakukan analisis terhadap tingkat loyalitas masyarakat terhadap layanan kesehatan yang mereka alami dan rasakan selama berinteraksi dengan pihak RSUD Kota Padang. Berikut ini adalah hasil penyesuaian data dengan model hipotesis terkait Model Loyalitas masyarakat tersebut. Model yang dihasilkan diilustrasikan pada Gambar 5 berikut.

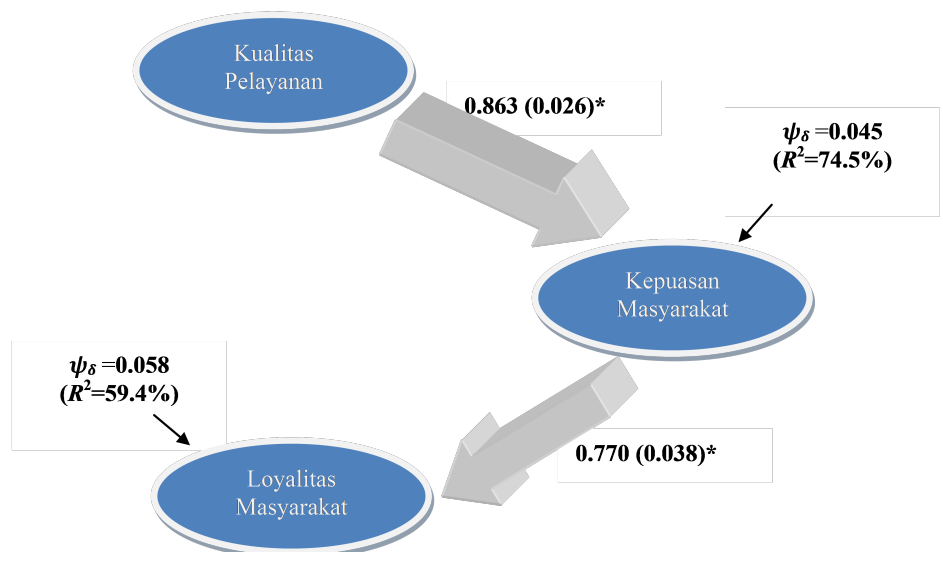

Gambar 5. Model Loyalitas Masyarakat Terhadap Layanan Kesehatan di RSUD Kota Padang

Berdasarkan model di atas diketahui bahwa kualitas pelayanan memberikan kontribusi dan pengaruh yang sangat besar terhadap tingkat kepuasaan masyarakat, yang ditandai dengan nilai pengaruhnya sebesar 0.855. Sedangkan tingkat kepuasan tersebut juga mempengaruhi loyalitas masyarakat cukup besar, yaitu 0.781, tetapi pengaruh ini tidak sebesar pengaruh kualitas pelayanan terhadap tingkat kepuasaan masyarakat. Informasi yang ditangkap dari hubungan ini adalah untuk meningkatkan tingkat kepuasaan masyarakat maka perlu ditingkatkan kualitas pelayanan. Sedangkan untuk meningkatkan loyalitas masyarakat maka tingkat kepuasaan dan kualitas pelayanan harus juga ditingkatkan.

Pada Tabel 1 ditampilkan nilai dugaan parameter, simpangan baku, dan $R 2$ untuk setiap model pengukuran yang dihasilkan. Informasi yang diperoleh dari tabel tersebut adalah bahwa kualitas pelayanan diukur secara signifikan oleh lima indikator yaitu kehandalan, daya tanggap, jaminan, empati dan bukti fisik, dimana kehandalan adalah indikator pengukur terbesar untuk kualitas pelayanan dibanding indikator yang lain. Sedangkan tingkat kepuasaan masyarakat diukur secara signifikan oleh harga yang sesuai, kemampuan dokter, perasaan senang setelah mendapat perawatan, pelayanan sesuai harapan dan pelayanan RSUD memuaskan. Dari lima indikator tersebut, indikator yang paling besar memberi pengaruh terhadap tingkat kepuasan masyarakat adalah pelayanan RSUD memuaskan. Oleh karena itu untuk meningkatkan kepuasan masyarakat, indikator ini harus dipertimbangkan un- 
Tabel 1. Nilai Dugaan Parameter, Simpangan Baku, dan R2 untuk setiap Model Pengukuran yang dihasilkan

\begin{tabular}{clcc}
\hline Variabel Laten & \multicolumn{1}{c}{ Variabel Indikator } & $\begin{array}{c}\text { Dugaan Parameter } \\
\text { (Simpangan Baku) }\end{array}$ & $R^{2}(\%)$ \\
\hline Kualitas & Kehandalan & $0.816(0.036)^{*}$ & 66,6 \\
Pelayanan $\left(\xi_{\mathbf{1}}\right)$ & Daya tanggap & $0.607(0.048)^{*}$ & 36,8 \\
& Jaminan & $0.767(0.033)^{*}$ & 58,8 \\
& Empati & $0.694(0.043)^{*}$ & 48,2 \\
& Bukti fisik & $0.623(0.044)^{*}$ & 38,8 \\
Kepuasan & Harga sesuai & & \\
Masyarakat $\left(\boldsymbol{\eta}_{\mathbf{1}}\right)$ & Kompetensi dokter & $0.552(0.054)^{*}$ & 30,4 \\
& Senang setelah menjalani perawatan & $0.801(0.051)^{*}$ & 64.2 \\
& Pelayanan sesuai harapan & $0.914(0.033)^{*}$ & 83,5 \\
& Pelayanan RSUD memuaskan & $0.949(0.023)^{*}$ & 90 \\
& & $0.921(0.025)^{*}$ & 84,8 \\
Loyalitas & Merekomendasikan RSUD kepada & & \\
Masyarakat & orang lain & $0.937(0.037)^{*}$ & 87,8 \\
$\left(\boldsymbol{\eta}_{\mathbf{2}}\right)$ & Sering membahas kualitas RSUD & $0.472(0.069)^{*}$ & 22.3 \\
& Menceritakan hal-hal positif & $0.768(0.049)^{*}$ & 59 \\
& Mengajak orang lain & $0.824(0.033)^{*}$ & 69,9 \\
\hline
\end{tabular}

*Signifikan pada tingkat kepercayaan 95\%

tuk terus dipertahankan dan ditingkatkan baru indikator-indikator lain.

Adapun untuk model konstruk loyalitas masyarakat, terdapat empat indikator yang mempengaruhi faktor laten ini secara signifikan. Urutan indikator dari yang paling besar memberi pengaruh sampai yang paling kecil pengaruhnya adalah merekomendasikan jasa di RSUD kepada orang lain, mengajak orang lain untuk datang berobat ke RSUD, menceritakan hal-hal positif mengenai jasa pelayanan di RSUD dan sering membahas tentang kualitas layanan RSUD dalam setiap pembicaraan.

Dari hasil olahan Mplus juga menampilkan nilai-nilai untuk indikator kebaikan model (goodnes of fit). Diperoleh untuk nilai RMSEA $=0.092$, CFI $=0.958$ and TLI $=0.982$, Berdasarkan nilai CFI dan TLI dibuktikan bahwa model dugaan yang dihasilkan adalah baik (karena lebih besar dari 0.95), sedangkan nilai RMSEA berada diluar rentang penerimaan (di atas 0.08).

Menurut Solimun (2005) jika ada satu atau lebih yang telah fit, maka model dikatakan fit. Sehingga dapat disimpulkan disini bahwa model dugaan yang dihasilkan adalah baik dan dapat diterima.

\section{Kesimpulan}

Dalam penelitian ini terdapat tiga variabel laten yang akan diukur dengan menggunakan variabel indikator, adapun variabel laten tersebut kualitas pelayanan, kepuasan masyarakat dan loyalitas masyarakat. Masing-masing variabel laten memiliki lebih dari dua variabel indikator. Data yang digunakan dalam penelitian ini ada sebesar 150 responden yaitu survei langsung kepada masyarakat yang pernah dan sedang menjalani perawatan di RSUD dr. Rasidin Padang. Analisis dijalankan dengan menggunakan software Mplus versi 5.2. Dari hasil penelitian diketahui bahwa 
kelima indikator pembentuk kualitas pelayanan RSUD terbukti berpengaruh secara signifikan terhadap kualitas pelayanan. indikator terkuat dalam menjelaskan kualitas pelayanan berturut-turut adalah kehandalan, jaminan, empati, bukti fisik, dan daya tanggap, untuk kepuasan ada lima indikator yang mempengaruhi dan ada empat indikator yang mempengaruhi loyalitas masyarakat.

Selain itu, dari hasil penelitian diketahui bahwa kualitas pelayanan memberikan kontribusi dan pengaruh yang sangat besar terhadap tingkat kepuasaan masyarakat, yang terbukti dari nilai pengaruhnya sebesar 0.830. Sedangkan tingkat kepuasan tersebut juga mempengaruhi loyalitas masyarakat cukup besar, yaitu 0.753, tetapi pengaruh loyalitas masyarakat tidak sebesar pengaruh kualitas pelayanan terhadap tingkat kepuasaan masyarakat. Hal ini berarti bahwa Informasi yang ditangkap dari hubungan ini adalah untuk meningkatkan tingkat kepuasaan masyarakat maka perlu ditingkatkan kualitas pelayanan. Sedangkan untuk meningkatkan loyalitas masyarakat maka tingkat kepuasaan dan kualitas pelayanan harus juga ditingkatkan. Indikator kebaikan model dapat dibuktikan bahwa model dugaan yang dhasilkan adalah baik dan dapat diterima.

\section{Daftar Pustaka}

[1] Bollen, K.A.1989. Structural Equations with Latent Variables. John Wiley and Sons, New York, NY

[2] Caruana, A. 2002. Service Loyalty The Effects of Service Quality and The Mediating Role of Customer Satisfaction. European Journal of Marketing, 36.

[3] Cooper, D.R., dan Schindler, P.S. 2006. Business Research Methods (9th ed.). New York: McGraw-Hill/Irwin. Boulding, W. et.al. 1993. A Dynamic Process Model Of Service Quality: From Expectations To.

[4] Ferdinand, A. 2000. Manajemen Pemasaran: Sebuah Pendekatan Strategi, Research Paper Series.

[5] Ferdinand, A. 2002. Structural Equation Modeling Dalam Penelitian Manajemen. Fakultas Ekonomi UNDIP. Semarang.

[6] Hair, J.F., R.E. Anderson, R.L. Thatam dan W.C. Black. 2010. Multivariate Data Analysis, 7th Edition. Englewood Cliffs, NJ: Prentice Hall.

[7] Malhotra, N.K. 2004. Marketing Research: An Applied Orientation. New Jersey: Pearson Education.

[8] Parasuraman A, Zeithaml V.A., Berry L. 1985. A conceptual model of service quality and its implications for future research. Journal of Marketing, 49(3): 41 $-50$

[9] Santoso, Singgih. 2007. Structural Equation Modelling: Konsep dan Aplikasi dengan AMOS Membuat dan Menganalisis Model SEM Menggunakan Program AMOS. Jakarta: PT. Elex Media Komputindo.

[10] Solimun. 2002. Multivariat Analysis Structrural Equation Modeling (SEM), LISREL dan Amos Aplikasi di Manajemen, Ekonomi Pembangunan, Psikologi, Sosial, Kedokteran dan Agrokompleks, Universitas Negeri Malang.

[11] Zeithmal, V. A., Berry, L.L. and Parasuraman, A. 1996. The Behavioral Consequences of Service Quality. Journal of Marketing 60 : $31-46$. 